\title{
HIV PREVALENCE, KNOWLEDGE AND SELF- PERCEIVED RISK OF HIV INFECTION AMONG TUBERCULOSIS PATIENTS IN SERBIA
}

\author{
Maja B. Stošić ${ }^{1}$, Danijela M. Simić1, Dragan D. Babić , Lidija Ristić $^{3}$, Vesna Kuruc ${ }^{4}$ \\ ${ }^{1}$ Department for HIV infection, STIs, Viral Hepatitis and TB, Public Health Institute of Serbia "Dr Milan Jovanovic Batut", Belgrade, Serbia \\ ${ }^{2}$ Institute of Medical Statistics and Informatics, School of Medicine, Belgrade, Serbia \\ ${ }^{3}$ Clinic for Pulmonary Disease, Clinical Centre of Niš, Niš, Serbia \\ ${ }^{4}$ Institute for Pulmonary Diseases of Vojvodina, Novi Sad, Serbia
}

\section{SUMMARY}

Objective: The aim of the study was to estimate the seroprevalence of HIV infection among TB patients, knowledge, self-perceived risks and testing practices related to HIV.

Methods: We performed cross-sectional study from 10 May to 15 July 2011. Cluster sampling method was used to select 27 hospitals where 289 TB patients were consecutively recruited. Descriptive statistics and multivariable logistic regression methods were used to identify the factors associated with correct comprehensive knowledge of HIVIAIDS.

Results: HIV prevalence among TB patients was $0.3 \%$. Only $25.2 \%$ of the respondents presented comprehensive correct knowledge of HIV/ AIDS. The percentage of correct answers to all questions related to knowledge about HIVIAIDS increases with educational status $\left(X^{2}=5.42\right.$; $p<0.05)$ and decreases with the age of respondents $\left(X^{2}=8.53 ; p>0.05\right)$. The independent predictors of correct comprehensive knowledge were living without partner $(\mathrm{OR}=4.45 ; \mathrm{Cl}=1.59-12.95)$ and self-awareness of HIV risk $(\mathrm{OR}=4.43 ; \mathrm{Cl}=1.20-16.52)$.

Conclusion: HIV prevalence among TB patients is higher than among general population in Serbia. The level of comprehensive correct knowledge of HIVIAIDS is low. There is a need for continuous implementation of public health strategy to successfully manage HIV and HIV/TB co-infection in Serbia.

Key words: tuberculosis, HIV, HIV/TB co-infection, prevalence, Serbia

Address for correspondence: M. Stosic, Public Health Institute of Serbia, St. Avalska 13, 11000 Belgrade, Serbia. E-mail: maja_stosic@batut.org.rs https://doi.org/10.21101/cejph.a4950

\section{INTRODUCTION}

The human immunodeficiency virus (HIV) pandemic presents a significant challenge to global tuberculosis (TB) control (1). At least one-third of people living with HIV worldwide is infected with latent tuberculosis (LTB). Persons co-infected with TB and HIV are 21-34 times more likely to develop tuberculosis (TB) than persons without HIV (2). TB is a leading preventable cause of death among people living with HIV (1).

In Serbia, since the beginning of the HIV/AIDS epidemic in 1985, as of December 2015, 3,312 people infected with HIV were registered. Out of them, 1,788 people were newly diagnosed with clinical signs of AIDS. Among HIV-positive people who were diagnosed with AIDS, in 350 persons (20\%) TB was registered as one of the associated infections. Pulmonary TB was reported in $35 \%$ of diagnosed TB/HIV co-infected cases. Dominant transmissible category of all registered TB/HIV coinfected patients were injecting drug users (49\%), while 35\% acquired HIV infection from unprotected sexual intercourse, regardless of relations with sexual partners of the same or op- posite sex. Among 1,086 HIV-positive people who died of AIDS in the period 1985-2015, TB was reported as a cause of death in $19 \%$ of cases (3).

Numerous studies indicate 5 to 10 times higher risk of active TB among people infected with HIV, and higher risk of dying among HIV-positive people suffering from TB (4-6). Moreover, it is shown among TB patients that increased risk of HIV infections have drug users, homeless, prisoners, and alcoholics $(7,8)$. In the era of HIV pandemic, there has been a significant increase in the incidence of sputum negative pulmonary TB associated with HIV (9-11).

In Serbia, routinely offering of HIV testing to TB patients has not been carried out. Additionally, targeted sero-epidemiological study among TB patients has never been performed to provide a good insight into the actual estimated prevalence of HIV infection.

The aim of the study was to estimate seroprevalence of HIV infection among TB patients, the level of knowledge, self-perceived risks, and testing practices related to HIV among TB patients in Serbia as a basis for development of public health strategy to jointly address HIV/TB co-infection. 


\section{MATERIALS AND METHODS}

We utilized a cross sectional design of a study with included biological/serological and behavioural components.

The biological component was based on the determination of serological status using a rapid HIV serological tests (determining the presence of specific anti-HIV antibodies in peripheral blood taken from fingertip).

Behavioural component was based on the determination of the level of knowledge, self-perceived risks and testing practices related to HIV, using structured questionnaire.

The survey in the field was performed from 10 May to 15 July 2011.

\section{Study Population}

Residents of Serbia aged 18 years and more, of both sexes, diagnosed with TB and hospitalized during the study period.

\section{Inclusion Criteria}

Confirmation (bacteriological or histopathological or clinical) of TB diagnosis according to the International Classification of Diseases (ICD-10) codes: A15 (A15.1-A15.9) respiratory TB proven bacteriologically and histologically, A16 (A16.1-A16.9) respiratory TB not confirmed bacteriologically or histologically, A18.2 TB of peripheral lymph nodes.

The mental ability of patients to understand the study purpose and procedures.

\section{Exclusion Criteria}

Confirmation of TB diagnosis (according to the International Classification of Diseases (ICD-10) codes: A17 - TB of nervous system, A18 (A18.0 and A18.3-A18.1-A18.8) - TB of other organs, and A19 - disseminated TB.

The cluster sample was applied in the study. The sampling frame consists of all in-patient health institutions in Serbia, where TB patients were hospitalized in 2009. The sample size was 450 eligible respondents for 2.5 months. Cluster size is about 20 (average number of patients treated at the hospital for 1 year). The number of respondents who provides the necessary sample size was calculated from the formula: $\mathrm{N}=\left(\mathrm{Z}^{2} \mathrm{PQ} / \mathrm{E}^{2}\right) * \operatorname{deff}(\mathrm{N}=$ the required minimum sample size; $\mathrm{P}=$ the expected proportion of respondents with characteristic; $\mathrm{Q}=100-\mathrm{P} ; \mathrm{E}=$ precision of estimates (limit of sampling error); $\mathrm{Z}=$ factor which corresponds to the desired confidence interval; deff (design effect).

\section{Study Instruments}

Biological component was performed based on laboratory protocol for determining the seroprevalence of HIV infection which contained descriptions of all necessary procedures. Study facilitators (doctors and nurses) were specially trained for the implementation.

The collection of behavioural data was performed using structured questionnaire comprising 20 closed-ended questions and including the following five groups of constructs:

- socio-demographic characteristics of the respondents;
- knowledge, attitudes and opinions about HIV/AIDS;

- HIV testing practices;

- state of health and knowledge about the diseases (indirect information about the risks for HIV infection);

- information about TB disease.

Interviewing was conducted face to face. It was performed by doctors who were trained on questionnaire administration prior to study initiation. Fundamental ethical principles were ensured: protecting the welfare of participants, respect for basic human rights, personality, integrity, dignity and autonomy of all participants, confidentiality, anonymity, and voluntariness. Voluntariness was ensured by asking participants to sign an informed consent form to confirm decision to participate in the study and separate consent form to be tested on HIV. The study was approved by the Ethic Committee of the Institute of Public Health of Serbia.

Data were entered and analysed using IBM SPSS Software V20.0. Descriptive statistical methods were performed (chi-square test, mean and standard deviation for continuous variables and frequencies for categorical variables). Multivariable logistic regression analysis was applied to identify the factors associated with correct knowledge related to HIV prevention and rejection of major misconceptions. The dependent variable in the analysis was correct knowledge of HIV prevention and rejection of misconceptions (coded 1). Confidence intervals (CI) for all bivariate odds ratios (OR) were $95 \%$, and they were adjusted for sex and age of patients. The level of significance in all applied methods was $\mathrm{p}<0.05$.

\section{RESULTS}

\section{Characteristics of Respondents}

A total of 310 TB patients were recruited, 21 were excluded from the study after assessing eligibility criteria. Out of the 289 patients who gave informed consent to participate in the study, two people did not give consent for HIV testing. Therefore, 287 TB patients were tested for HIV. TB diagnosis was confirmed by sputum smear microscopy in $42.2 \%$ of respondents, in $74.2 \%$ by culture, in $6.3 \%$ histologically, and clinically in $8.4 \%$ of respondents. More than two thirds of respondents were males $\left(\chi^{2}=4.97\right.$; $\mathrm{p}<0.01)$. More than four-fifths of them were newly diagnosed TB cases $\left(\chi^{2}=4.97 ; \mathrm{p}>0.05\right)$. Pulmonary TB was diagnosed in $96.5 \%$ of respondents $\left(\chi^{2}=6.60 ; p>0.05\right)$.

Average age of the male respondents was $51.73(\mathrm{SD}=15.86)$ and female respondents $50.21(\mathrm{SD}=21.01)(\mathrm{t}=0.69 ; \mathrm{p}<0.05)$. Half of the respondents were married $\left(\chi^{2}=12.30 ; p<0.05\right)$ while almost half of them completed high school $\left(\chi^{2}=71.06 ; \mathrm{p}<0.01\right)$. The proportion of unemployed respondents were almost twice as high than the percentage of retirees $\left(\chi^{2}=140.92 ; p<0.01\right)$. One fifth of the respondents reported having no source of cash income $\left(\chi^{2}=141.47 ; p<0.01\right)$. Chronic bronchitis and asthma $(16.5 \%)$ and diabetes $(11.1 \%)$ were reported as the most frequent comorbidity conditions among respondents (Table 1).

\section{HIV Status}

Preliminary testing on HIV (determining presence of anti-HIV antibodies) using rapid HEXAGON HIV test was conducted in 
Table 1. Characteristics of respondents by age $(N=310)$

\begin{tabular}{|c|c|c|c|c|c|c|c|}
\hline Variables & All & Age 18-29 & Age $30-39$ & Age $40-49$ & Age 50-59 & Age $\geq 60$ & $\mathrm{p}$-value \\
\hline Gender, $n(\%)$ & $310(100)$ & $39(12.6)$ & $50(16.1)$ & $48(15.5)$ & $76(24.5)$ & $97(31.3)$ & $<0.01^{* *}$ \\
\hline Male & $219(70.6)$ & $4(26.7)$ & $10(66.7)$ & $11(100.0)$ & $19(90.5)$ & $11(68.8)$ & \multirow{2}{*}{$<0.01^{* *}$} \\
\hline Female & $91(29.4)$ & $11(73.3)$ & $5(33.3)$ & $0(0.0)$ & $2(9.5)$ & $5(31.2)$ & \\
\hline \multicolumn{8}{|l|}{ Age, mean (SD) } \\
\hline Male & \multicolumn{6}{|c|}{$51.73(\mathrm{SD}=15.86)$} & \multirow{2}{*}{0.49} \\
\hline Female & \multicolumn{6}{|c|}{$50.21(S D=21.01)$} & \\
\hline Marital status, $n(\%)$ & $289(100)$ & & & & & & \\
\hline Married/living with partner & $151(52.2)$ & $11(28.2)$ & $25(55.6)$ & $23(51.1)$ & $39(52.7)$ & $53(61.6)$ & \multirow{2}{*}{$0.02^{*}$} \\
\hline Living without partner ${ }^{a}$ & $138(47.8)$ & $28(71.8)$ & $20(44.4)$ & $22(48.9)$ & $35(47.3)$ & $33(38.4)$ & \\
\hline Education, n (\%) & $289(100)$ & & & & & & \\
\hline No elementary school & $59(20.4)$ & $3(7.7)$ & $1(2.2)$ & $4(8.9)$ & $13(17.6)$ & $38(44.2)$ & \multirow{4}{*}{$<0.01^{* *}$} \\
\hline Elementary & $77(26.6)$ & $8(20.5)$ & $9(20.0)$ & $18(40.0)$ & $21(28.4)$ & $21(24.4)$ & \\
\hline Secondary & $129(44.6)$ & $25(64.1)$ & $30(66.7)$ & $22(48.9)$ & $36(48.6)$ & $16(18.6)$ & \\
\hline University & $24(8.3)$ & $3(7.7)$ & $5(11.1)$ & $1(2.2)$ & $4(5.4)$ & $11(12.8)$ & \\
\hline Employment, n (\%) & $289(100)$ & & & & & & \\
\hline Employed & $64(22.1)$ & $13(33.4)$ & $21(46.6)$ & $8(17.8)$ & $18(24.3)$ & $4(4.7)$ & \multirow{4}{*}{$<0.01^{* *}$} \\
\hline Retiree & $84(29.1)$ & $0(0.0)$ & $1(2.2)$ & $9(20.0)$ & $12(16.2)$ & $62(72.1)$ & \\
\hline Student & $4(1.4)$ & $2(5.1)$ & $1(2.2)$ & $1(2.2)$ & $0(0.0)$ & $0(0.0)$ & \\
\hline Unemployed & $137(47.4)$ & $24(61.5)$ & $22(48.9)$ & $27(60.0)$ & $44(59.5)$ & $20(23.3)$ & \\
\hline Income source, n (\%) & $289(100)$ & & & & & & \\
\hline Salary & $96(33.2)$ & $15(38.4)$ & $26(55.6)$ & $14(31.1)$ & $25(33.8)$ & $16(18.7)$ & \multirow{4}{*}{$<0.01^{* *}$} \\
\hline Retirement & $78(27.0)$ & $1(2.6)$ & $1(2.2)$ & $7(15.6)$ & $13(17.6)$ & $56(65.1)$ & \\
\hline Social welfare & $18(6.2)$ & $2(5.1)$ & $1(2.2)$ & $6(13.3)$ & $7(9.5)$ & $2(33.2)$ & \\
\hline No income & $62(21.5)$ & $15(38.5)$ & $8(17.8)$ & $12(26.7)$ & $19(25.7)$ & $8(9.3)$ & \\
\hline TB category, n (\%) & $289(100)$ & & & & & & \\
\hline New cases & $246(85.1)$ & $35(89.7)$ & $42(93.3)$ & $37(82.2)$ & $63(85.1)$ & 69 (80.2) & \multirow{2}{*}{0.30} \\
\hline Previously treated cases & $43(14.9)$ & $4(10.3)$ & $3(6.7)$ & $8(17.8)$ & $11(14.9)$ & $17(19.8)$ & \\
\hline TB localization, n (\%) & $289(100)$ & & & & & & \\
\hline Pulmonary & $279(96.5)$ & $36(92.3)$ & $43(95.6)$ & $45(100.0)$ & $72(97.3)$ & $83(96.5)$ & \multirow{2}{*}{0.59} \\
\hline Extra-pulmonary & $10(4.5)$ & $3(7.7)$ & $2(4.4)$ & $0(0.0)$ & $2(2.7)$ & $3(3.5)$ & \\
\hline Comorbidities, n (\%) & $289(100)$ & & & & & & \\
\hline Chronic bronchitis or asthma & $51(16.5)$ & $1(2.6)$ & $6(13.3)$ & $12(26.7)$ & $10(13.5)$ & $22(25.6)$ & $<0.01^{* *}$ \\
\hline Diabetes & $32(11.1)$ & $1(2.6)$ & $1(2.2)$ & $4(8.9)$ & $8(10.8)$ & $18(20.09)$ & $<0.01^{* *}$ \\
\hline Hepatitis C & $5(1.7)$ & $1(2.6)$ & $1(2.2)$ & $1(2.2)$ & $0(0.0)$ & $2(2.3)$ & 0.78 \\
\hline Hepatitis B & $2(0.7)$ & $0(0.0)$ & $1(2.2)$ & $0(0.0)$ & $0(0.0)$ & $1(1.2)$ & 0.57 \\
\hline STDs & $2(0.7)$ & $1(2.6)$ & $0(0.0)$ & $0(0.0)$ & $0(0.0)$ & $1(1.2)$ & 0.49 \\
\hline
\end{tabular}

anmarried, divorced, widowed

${ }^{*} p<0.05,{ }^{* *} p<0.01$

287 respondents. Mandatory counselling before blood sampling and while communication of test results has been performed by trained healthcare workers. Conventional ELISA and Western blot test were used for confirmation of a case of carrying antiHIV antibodies.

During the study only one HIV positive respondent was confirmed, making estimated HIV prevalence of $0.3 \%(\mathrm{CI}=0.29$ 0.41). HIV infected respondent was male aged 30-39, diagnosed with sputum negative pulmonary TB, he completed high school and was unemployed. He did not correctly identify ways of pre- venting sexual transmission of HIV and reject misconceptions regarding HIV transmission.

\section{Knowledge about HIV/AIDS, Self-Perceived Risk and Testing Practices}

Although majority of respondents $(88.9 \%)$ have heard about HIV/AIDS, significant difference is noticed among age groups $\left(\chi^{2}=16.47 ; p<0.01\right)$, the lowest level of knowledge is reported in $60+$ age group of patients, as presented in Table 2. 
Table 2. Knowledge about HIVIAIDS, self-perceived risk and testing practices $(N=289)$

\begin{tabular}{|c|c|c|c|c|c|c|c|}
\hline Question & All & Age 18-29 & Age $30-39$ & Age $40-49$ & Age $50-59$ & Age $\geq 60$ & $\mathrm{p}$-value \\
\hline $\begin{array}{l}\text { Have you ever heard of HIV virus or of AIDS } \\
\text { disease caused by this virus? } n(\%)\end{array}$ & $289(100)$ & & & & & & \\
\hline Yes & $257(88.9)$ & 37 (94.9) & $44(97.8)$ & 41 (91.1) & 68 (91.9) & 67 (77.9) & \multirow{2}{*}{$<0.01^{* *}$} \\
\hline No & $32(11.1)$ & $2(5.1)$ & $1(2.2)$ & $4(8.9)$ & $6(8.1)$ & $19(22.1)$ & \\
\hline $\begin{array}{l}\text { Does practicing sexual relations with only one, } \\
\text { uninfected partner reduce the risk of HIV } \\
\text { transmission? } \mathrm{n}(\%)\end{array}$ & $257(100)$ & & & & & & \\
\hline Correct answer & $197(76.7)$ & $31(83.8)$ & 37 (84.1) & 34 (82.9) & $53(77.9)$ & $42(62.7)$ & \multirow{3}{*}{$<0.01^{* *}$} \\
\hline Misconception & $22(8.6)$ & $3(8.1)$ & $7(15.9)$ & $3(7.3)$ & $5(7.4)$ & $4(6.0)$ & \\
\hline Don't know & 38 (14.8) & $3(8.1)$ & $0(0.0)$ & $4(9.8)$ & $10(14.7)$ & $21(31.3)$ & \\
\hline $\begin{array}{l}\text { Does the correct use of condoms during each } \\
\text { sexual intercourse reduce the risk of HIV } \\
\text { transmission? } n(\%)\end{array}$ & $257(100)$ & & & & & & \\
\hline Correct answer & $200(77.8)$ & $35(94.6)$ & 41 (93.2) & $34(82.9)$ & $57(83.8)$ & $33(49.3)$ & \multirow{3}{*}{$<0.01^{* *}$} \\
\hline Misconception & $8(3.1)$ & $0(0.0)$ & $1(2.3)$ & $0(0.0)$ & $4(5.9)$ & $3(4.5)$ & \\
\hline Don't know & 49 (19.1) & $2(5.4)$ & $2(4.5)$ & $7(17.1)$ & $7(10.3)$ & $31(46.3)$ & \\
\hline $\begin{array}{l}\text { Does person who look healthy can be HIV } \\
\text { infected? } n(\%)\end{array}$ & $257(100)$ & & & & & & \\
\hline Correct answer & $187(72.8)$ & 30 (81.1) & 39 (88.6) & $28(68.3)$ & $55(80.9)$ & 35 (52.2) & \multirow{3}{*}{$<0.01^{* *}$} \\
\hline Misconception & $10(3.9)$ & $4(10.8)$ & $1(2.3)$ & $2(4.9)$ & $1(1.5)$ & $2(3.0)$ & \\
\hline Don't know & $60(23.3)$ & $3(8.1)$ & $4(9.1)$ & $11(26.8)$ & $12(17.6)$ & $30(44.8)$ & \\
\hline $\begin{array}{l}\text { Whether a person can become HIV infected stay- } \\
\text { ing in the same living or working space with HIV } \\
\text { infected person? } n(\%)\end{array}$ & $257(100)$ & & & & & & \\
\hline Correct answer & $149(58.0)$ & $24(64.9)$ & $37(84.1)$ & $25(61.0)$ & $35(51.5)$ & $28(41.8)$ & \multirow{3}{*}{$<0.01^{* *}$} \\
\hline Misconception & 49 (19.1) & $7(18.9)$ & $4(9.1)$ & $6(14.6)$ & $15(22.1)$ & $17(25.4)$ & \\
\hline Don't know & $59(23.0)$ & $6(16.2)$ & $3(6.8)$ & $10(24.4)$ & $18(26.5)$ & $22(32.8)$ & \\
\hline $\begin{array}{l}\text { Whether a person can become infected with HIV } \\
\text { sharing food with HIV infected person? } \mathrm{n}(\%)\end{array}$ & $257(100)$ & & & & & & \\
\hline Correct answer & $133(51.8)$ & $20(54.1)$ & $26(59.1)$ & $28(68.3)$ & $35(51.5)$ & $24(35.8)$ & \multirow{3}{*}{0.11} \\
\hline Misconception & $52(20.2)$ & $7(18.9)$ & $9(20.5)$ & $4(9.8)$ & $14(20.6)$ & $18(26.9)$ & \\
\hline Don't know & $72(28.0)$ & $10(27.0)$ & $9(20.5)$ & $9(22.0)$ & $19(27.9)$ & $25(37.3)$ & \\
\hline $\begin{array}{l}\text { Does HIV infected person have a higher risk of } \\
\text { developing TB? } n(\%)\end{array}$ & $257(100)$ & & & & & & \\
\hline Correct answer & $156(60.7)$ & $23(62.2)$ & $32(72.7)$ & $22(53.7)$ & $39(57.4)$ & $40(59.7)$ & \multirow{3}{*}{0.62} \\
\hline Misconception & $13(5.1)$ & $2(5.4)$ & $3(6.8)$ & $3(7.3)$ & $2(2.9)$ & $3(4.5)$ & \\
\hline Don't know & $88(34.2)$ & $12(32.4)$ & $9(20.5)$ & $16(39.0)$ & $27(39.7)$ & $24(35.8)$ & \\
\hline Have you ever been tested for HIV? n (\%) & $257(100)$ & & & & & & \\
\hline Yes & $39(15.2)$ & $7(18.9)$ & $17(38.6)$ & $8(19.5)$ & $6(8.8)$ & $1(1.5)$ & \multirow{2}{*}{$<0.01^{* *}$} \\
\hline No & $218(84.8)$ & $30(81.1)$ & $27(61.4)$ & $33(80.5)$ & $62(91.2)$ & $66(98.5)$ & \\
\hline $\begin{array}{l}\text { Do you think you are at risk of being infected by } \\
\text { HIV virus? } n(\%)\end{array}$ & $122(100)$ & & & & & & \\
\hline Yes & $23(18.9)$ & $3(16.7)$ & $8(30.8)$ & $1(6.2)$ & $5(16.7)$ & $6(18.8)$ & \multirow{3}{*}{0.60} \\
\hline No & $73(59.8)$ & $10(55.6)$ & $13(50.0)$ & $13(81.2)$ & $19(63.3)$ & 18 (56.2) & \\
\hline Don't know & $26(21.3)$ & $5(27.8)$ & $5(19.2)$ & $2(12.5)$ & $6(20.0)$ & $8(25.0)$ & \\
\hline
\end{tabular}

${ }^{*} p<0.05,{ }^{* *} p<0.01$

Majority of respondents correctly identified ways of preventing HIV sexual transmission: $76.7 \%$ knew that practicing sexual relations with only one, uninfected partner reduces the risk of HIV transmission, the differences among age groups are presented $\left(\chi^{2}\right.$ $=26.74 ; \mathrm{p}<0.01)$. Significantly higher percentage of those who responded correctly were married or living with partner (82.4\%). 
High proportion of respondents $(77.8 \%)$ knew that correct use of condoms during each sexual intercourse reduces the risk of HIV transmission, with significantly higher percentage $(94.6 \%)$ in patients aged $18-29$ years $\left(\chi^{2}=52.08 ; \mathrm{p}<0.01\right)$.

Less than three quarters of respondents $(72.8 \%)$ knew that person who look healthy can be infected with $\operatorname{HIV}\left(\chi^{2}=34.45\right.$; $\mathrm{p}<0.01$ ).

Only half of the respondents rejected misconception that a person can become HIV infected by staying in the same living or working space with HIV infected person - differences among age groups persist $\left(\chi^{2}=22.48 ; \mathrm{p}<0.01\right)$, or by sharing food with HIV infected person - no age group differences $\left(\chi^{2}=13.18\right.$; $\mathrm{p}>0.05)$. Existence of the risk of becoming ill from TB among HIV infected persons was correctly identified by only $61 \%$ of respondents $\left(\chi^{2}=6.27 ; p>0.05\right)$. Only one fourth of the respondents $(25.2 \%)$ correctly identified ways of preventing sexual transmission of HIV and at the same time reject misconceptions regarding HIV transmission. There is significant difference in knowledge related to HIV/AIDS among men and women and among age groups $\left(\chi^{2}=5.91 ; p<0.05\right)$, particularly in the age group 18-29 $(\mathrm{OR}=6.09 ; \mathrm{CI}=1.28-7.33)$ and 40-49 $(\mathrm{OR}=3.99$; $\mathrm{CI}=1.01-6.96)$. The percentage of correct answers to all questions related to knowledge about HIV/AIDS increases with educational status $\left(\chi^{2}=5.42 ; \mathrm{p}<0.05\right)$ and decreases with the age of respondents $\left(\chi^{2}=8.53 ; \mathrm{p}>0.05\right)$.

\section{Previous HIV Testing}

Previous HIV testing was reported by $15.2 \%$ of respondents, significant differences were noticed among age groups $\left(\chi^{2}=31.69\right.$; $\mathrm{p}<0.01$ ). Higher proportion of previous HIV testing was reported by patients aged $30-39$ years $(38.6 \%)$, as well as by those who live without partner $(19.2 \%)$. One fifth of the respondents reported risk of being infected with HIV $\left(\chi^{2}=6.48 ; p>0.05\right)$. Almost half of the previously HIV tested respondents $(46.2 \%)$ believe that there is no risk of being infected with HIV, $23.1 \%$ believe that risk exists, while $21.3 \%$ do not know.

The multivariable logistic regression analysis was performed to identify factors associated with correct knowledge of HIV prevention and rejection of misconceptions related to HIV (Ta-

Table 3. Multivariable logistic regression analysis (outcome variables correct knowledge of HIV prevention and rejection of misconceptions)

\begin{tabular}{|c|c|c|c|c|}
\hline \multirow{2}{*}{ Variable } & \multirow{2}{*}{ Adjusted OR } & \multicolumn{2}{|c|}{$95 \%$ Confidence Interval } & \multirow{2}{*}{$\mathrm{p}$-value } \\
\hline & & Lower limit & Upper limit & \\
\hline \multicolumn{5}{|l|}{ Gender } \\
\hline Male & 1.14 & 0.69 & 2.22 & 0.69 \\
\hline Female & 1.04 & 0.97 & 1.11 & 0.28 \\
\hline \multicolumn{5}{|l|}{ Marital status } \\
\hline Married/living with partner & 2.23 & 0.99 & 5.03 & 0.05 \\
\hline Living without partnera & 4.54 & 1.59 & 12.95 & $<0.01^{* *}$ \\
\hline \multicolumn{5}{|l|}{ Education } \\
\hline No elementary school & 0.30 & 0.08 & 1.05 & 0.06 \\
\hline Elementary & 0.83 & 0.29 & 2.43 & 0.74 \\
\hline Secondary & 1.20 & 0.44 & 3.30 & 0.72 \\
\hline University & 0.15 & 0.10 & 0.90 & 0.50 \\
\hline \multicolumn{5}{|l|}{ Employment } \\
\hline Employed & 1.23 & 0.47 & 3.23 & 0.68 \\
\hline Retiree & 0.50 & 0.05 & 5.32 & 0.57 \\
\hline Student & 0.49 & 0.17 & 1.45 & 0.20 \\
\hline Unemployed & 3.12 & 0.26 & 37.09 & 0.37 \\
\hline \multicolumn{5}{|l|}{ Income source } \\
\hline Salary & 1.39 & 0.43 & 4.43 & 0.58 \\
\hline Retirement & 0.94 & 0.36 & 2.44 & 0.90 \\
\hline Social welfare & 0.68 & 0.16 & 2.93 & 0.60 \\
\hline No income & 2.28 & 0.90 & 5.83 & 0.09 \\
\hline \multicolumn{5}{|l|}{ Comorbidities } \\
\hline Chronic bronchitis or asthma & 1.01 & 0.47 & 2.20 & 0.98 \\
\hline Diabetes & 2.12 & 0.78 & 5.78 & 0.14 \\
\hline Self-awareness of the risk of HIV infection & 4.43 & 1.20 & 16.52 & $0.03^{*}$ \\
\hline
\end{tabular}

aUnmarried, divorced, widowed

${ }^{*} p<0.05,{ }^{* *} p<0.01$

Outcome variables correct knowledge of HIV prevention and rejection of misconceptions 
ble 3). The independent predictors of correct knowledge of HIV prevention and rejection of misconceptions were living without partner $(\mathrm{OR}=4.45 ; \mathrm{CI}=1.59-12.95)$ and self-awareness of risk of being infected with $\mathrm{HIV}(\mathrm{OR}=4.43$; $\mathrm{CI}=1.20-16.52)$.

\section{DISCUSSION}

Although we found low seroprevalence of HIV among TB patients, the findings are considered important, having in mind higher WHO estimates (12) and absence of national baseline data. The HIV prevalence among TB patients was at minimum three times higher compared to the estimated prevalence of HIV infection among population over 15 years in Serbia (less than $0.1 \%$ ), and ten times higher than the registered prevalence of HIV infection in the general population at the end of $2015(0.03 \%)$ $(13,14)$. This finding is consistent with results reported in Balkan countries (excluding Romania with significantly higher TB/HIV prevalence, $3 \%)(15,16)$, lower than HIV prevalence among TB patients in both EU/EEA and non-EU/EEA countries (17). Studies conducted in Africa found much higher prevalence of HIV infection among TB patients $(38 \%)(11,18)$ as well as Chen et al. (19) study in China. Sex and age distribution of TB patients, with predominately males affected, as well as domination of new cases of TB pulmonary forms are similar to other countries in Europe $(20,21)$. Our study showed high unemployment rate and low level of household income among TB patients suggesting a need for broad poverty alleviation measures to effectively overcome the barriers in access to health care (22).

The study showed moderate level of knowledge related to HIV/ AIDS among TB patients. It is significantly higher than general population in Serbia (50\%) (23). So far, there are no studies in the European region focusing on this issue. Calderón et al. (24) reported lower level of knowledge in general population in Bolivia as well as Navaratna et al. (25) study in Sri Lanka, but Ethiopian study reported significantly higher level of knowledge (26).

Higher percentage of TB patients from our study reject major misconceptions related to HIV than general population in Serbia (23). It is lower than TB patients from Deribew et al. study conducted in Ethiopia, a country with high HIV prevalence (26). The percentage of TB patients who correctly identify ways of preventing sexual transmission of HIV and at the same time reject misconceptions regarding HIV transmission is low, almost the same as general population aged 15-24 (23). A moderate level of knowledge was identified in the study regarding higher risk of developing TB among HIV infected people. Previous HIV testing among TB patients is twice as frequent as among general population in Serbia (23) but significantly lower than EU/EEA countries (17).

Our study identified living without partner and self-awareness of risk related to HIV infection as independent predictors of correct knowledge of HIV prevention and rejection of misconceptions among TB patients. Other studies identified sex, level of education (27) and sexual activity (28) as independent predictors of correct knowledge of HIV prevention and rejection of misconceptions.

\section{Study Limitations}

It was not feasible to include other forms of extra-pulmonary $\mathrm{TB}$ respondents (TB of the nervous system and other organs except the peripheral lymph nodes) due to territory distribution and limitations in costs and time. Information related to sexual activity and illegal drugs/psychoactive substances consumption were also not available.

\section{CONCLUSIONS}

Periodic surveys of seroprevalence of HIV infection among TB patients should be conducted in order to monitor trends, risk factors and determinants of TB/HIV co-infection in Serbia.

It is necessary to implement integrated programme measures related to prevention, care and support of people affected by HIV infection and TB. First, health service provider should initiate voluntary and confidential counselling and testing for HIV for all TB patients, particularly those under 50 years of age or people with certain risk for sexually transmitted infections (STI) and HIV infection. Second, we should perform continuous trainings of all medical and non-medical workers who deal with TB and HIV infection, as well as develop joint TB/HIV programme communication and social mobilization strategy.

\section{Conflict of Interests}

None declared

\section{Author Contributions}

Study design: MBS, DMS; data analysis: DDB, MBS; the first draft of the manuscript: MBS; contributed to the writing of the manuscript: MBS, DMS, DDB, LR, VK; agreed with the manuscript results and conclusions: MBS, DMS, DDB, LR, VK; jointly developed the structure and arguments for the paper: MBS, DMS, DDB, LR, VK; made critical revisions and approved final version: MBS, DMS, DDB, LR, VK.

Dragan Ilić participated in the development of the structure and arguments for the paper, made critical revisions, and agreed with the manuscript results and conclusions. Dragan Ilić, Doc, M.D, M.P.H., Ph.D. passed away on 20 September 2016.

\section{Adherence to Ethical Standards}

All procedures performed in studies involving human participants were in accordance with the ethical standards of the institutional and/or national research committee and with the 1964 Helsinki declaration and its later amendments or comparable ethical standards.

\section{REFERENCES}

1. World Health Organization. WHO policy on collaborative TB/HIV activities: guidelines for national programmes and other stakeholders. Geneva: WHO; 2012.

2. World Health Organization. TB/HIV facts 2012-2013 [Internet]. Geneva: WHO [cited 2019 Mar 7]. Available from: http://www.who.int/hiv/topics/ tb/tbhiv facts 2013/en/.

3. Institute of Public Health of Serbia "Dr Milan Jovanović Batut". Report on Communicable Diseases in Serbia in 2015 [Internet]. Belgrade: IPHS; 2016 [cited 2019 Mar 7]. Available from: http://www.batut.org.rs/download/izvestaji/Zarazne\%20bolesti\%20godisnji\%20izvestaj\%202015.pdf.

4. Hiregoudar V, Raghavendra B, Karinagannavar A, Khan W, Kamble S, Goud TG. Proportion and determinants of tuberculosis among human immunodeficiency virus-positive patients attending the antiretroviral therapy center attached to a Medical College in South India. J Family Community Med. 2016 May-Aug; 23(2):88-93. 
5. Diedrich CR, O'Hern J, Wilkinson RJ. HIV-1 and the Mycobacterium tuberculosis granuloma: A systematic review and meta-analysis. Tuberculosis (Edinb). 2016 May;98:62-76.

6. Mekonnen D, Derbie A, Desalegn E. TB/HIV co-infections and associated factors among patients on directly observed treatment short course in Northeastern Ethiopia: a 4 years retrospective study. BMC Res Notes. 2015 Nov 11;8:666. doi: 10.1186/s13104-015-1664-0.

7. Zheng Z, Tang Z, Lu Q, Wei H, Geng W. Influential factors analysis on the survival time of patients infected with tuberculosis and HIV. Zhonghua Yu Fang Yi Xue Za Zhi. 2015 Oct;49(10):907-13.

8. Efsen AM, Schultze A, Post FA, Panteleev A, Furrer H, Miller RF, et al.; TB:HIV study group in EuroCoord. Major challenges in clinical management of TB/HIV coinfected patients in Eastern Europe compared with Western Europe and Latin America. PLoS One. 2015 Dec 30;10(12):e0145380. doi: 10.1371/journal.pone.0145380.

9. Campos LC, Rocha MV, Willers DM, Silva DR. Characteristics of patients with Smear-Negative Pulmonary Tuberculosis (TB) in a region with High TB and HIV prevalence. PLoS One. 2016 Jan 25;11(1):e0147933. doi: 10.1371/journal.pone.0147933.

10. Munthali L, Khan PY, Mwaungulu NJ, Chilongo F, Floyd S, Kayange $\mathrm{M}$, et al. The effect of HIV and antiretroviral therapy on characteristics of pulmonary tuberculosis in northern Malawi: a cross-sectional study. BMC Infect Dis. 2014 Feb 25;14:107. doi: 10.1186/1471-2334-14-107.

11. Belay M, Bjune G, Abebe F. Prevalence of tuberculosis, HIV, and TBHIV co-infection among pulmonary tuberculosis suspects in a predominantly pastoralist area, northeast Ethiopia. Glob Health Action. 2015 Dec 18;8:27949. doi: 10.3402/gha.v8.27949.

12. World Health Organization. Estimated HIV prevalence among TB cases [Internet]. Geneva: WHO; 2011 [cited 2019 Mar 7]. Available from: http:// www.who.int/hiv/topics/tb/HIVprevalence TBcases 2011.JPG?ua=1.

13. Current epidemiological situation regarding HIV infection in the Republic of Serbia [Internet]. Belgrade: Institute of Public Health of Serbia; 2011 [cited 2019 Mar 7]. Available from: http://www.batut.org.rs/index. php?content=254. (In Serbian.)

14. Republic of Serbia, Ministry of Health of Serbia, Institute of Public Health of Serbia "Dr Milan Jovanovic Batut". Serbia global AIDS response progress report 2016. Reporting period: January - December 2015 [Internet]. UNAIDS; 2016 [cited 2019 Mar 7]. Available from: http:/www.unaids.org/sites/default/files/country/documents/SRB narrative_report_2016.pdf.

15. World Health Organization. Global tuberculosis report 2012. Geneva: WHO; 2012.

16. World Health Organization. Global AIDS response progress reporting 2012. Geneva: WHO; 2012.
17. European Centre for Disease Prevention and Control; WHO Regional Office for Europe. Tuberculosis surveillance and monitoring in Europe 2012. Stockholm: ECDC; 2012.

18. Nsagha DS, Pokam BT, Assob JC, Njunda AL, Kibu OD, Tanue EA, et al. HAART, DOTS and renal disease of patients co-infected with HIV/ AIDS and TB in the South West Region of Cameroon. BMC Public Health. 2015 Oct 9;15:1040. doi: 10.1186/s12889-015-2331-z.

19. Chen J, Cao W, Chen R, Ren Y, Li T. Prevalence and determinants of HIV in tuberculosis patients in Wuxi City, Jiangsu province, China: a cross-sectional study. Int J STD AIDS. 2016 Nov;27(13):1204-12.

20. Karo B, Hauer B, Hollo V, van der Werf MJ, Fiebig L, Haas W. Tuberculosis treatment outcome in the European Union and European Economic Area: an analysis of surveillance data from 2002-2011. Euro Surveill. 2015 Dec 10;20(49). doi: 10.2807/1560-7917.ES.2015.20.49.30087.

21. Korzeniewska-Koseła M. Tuberculosis in Poland in 2013. Przegl Epidemiol. 2015;69(2):277-82.

22. Raviglione M, Sulis G. Tuberculosis 2015: Burden, challenges and strategy for control and elimination. Infect Dis Rep. 2016 Jun 24;8(2):6570. doi: 10.4081/idr.2016.6570.

23. Institute of Public Health of Serbia "Dr Milan Jovanović Batut". Results of the National Health Survey of the Republic of Serbia 2013 [Internet]. Belgrade: IPHS; 2014 [cited 2019 Mar 7]. Available from: http://www. batut.org.rs/download/publikacije/2013SerbiaHealthSurvey.pdf.

24. Terán Calderón C, Gorena Urizar D, González Blázquez C, Alejos Ferreras B, Ramírez Rubio O, Bolumar Montrull F, et al. Knowledge, attitudes and practices on HIV/AIDS and prevalence of HIV in the general population of Sucre, Bolivia. Braz J Infect Dis. 2015 Jul-Aug;19(4):369-75.

25. Navaratna S, Kanda K, Dharmaratne SD, Tennakoon S, Jayasinghe A, Jayasekara N, et al. Awareness and attitudes towards HIV/AIDS among residents of Kandy, Sri Lanka. AIDS Care. 2015;27(3):387-91.

26. Deribew A, Abebe G, Apers L, Jira C, Tesfaye M, Shifa J, et al. Prejudice and misconceptions about tuberculosis and HIV in rural and urban communities in Ethiopia: a challenge for the TB/HIV control program. BMC Public Health. 2010 Jul 6;10:400. doi: 10.1186/1471-2458-10-400.

27. Zainiddinov H, Habibov N. Trends and predictors of knowledge about HIV/AIDS and its prevention and transmission methods among women in Tajikistan. Eur J Public Health. 2016 Dec;26(6):1075-9.

28. Brito MO, Davis M, Chakrabarti A. A cross-national study to compare the knowledge, attitudes, perceptions of sexually transmitted diseases and the sexual risk behaviors of Latino adolescents. Int J Adolesc Med Health. 2014;26(2):203-8.

Received October 17, 2016 Accepted in revised form March 7, 2019 